Research Article

\title{
Defining Stress Thresholds of Granite Failure Process Based on Acoustic Emission Activity Parameters
}

\author{
Xingdong Zhao, Lei Deng ${ }^{(D)}$, and Jitao Xu \\ Geomechanics Research Center, Northeastern University, Shenyang 110819, China \\ Correspondence should be addressed to Lei Deng; denglei635@126.com
}

Received 26 May 2020; Revised 29 June 2020; Accepted 14 July 2020; Published 28 July 2020

Academic Editor: Qing Ma

Copyright (c) 2020 Xingdong Zhao et al. This is an open access article distributed under the Creative Commons Attribution License, which permits unrestricted use, distribution, and reproduction in any medium, provided the original work is properly cited.

\begin{abstract}
In order to study the crack closure stress threshold $\sigma_{c c}$ of hard rock, crack initiation stress threshold $\sigma_{c i}$, stress threshold $\sigma_{c s}$ of crack interaction, and damage stress threshold $\sigma_{c d}$, uniaxial compression test was carried out on granite samples. Stress sensor and dynamic strain gauge are used to measure the load, longitudinal, and lateral deformation of rock in real time. The acoustic emission characteristic parameters of rock fracture process are obtained by using the acoustic emission system. According to the change rule of the AE event rate, cumulative energy, energy rate, duration, and amplitude in the whole process of granite sample fracture, the stress threshold $\left(\sigma_{c c}, \sigma_{c i}, \sigma_{c s}\right.$, and $\left.\sigma_{c d}\right)$ of each loading stage in the process of rock sample fracture is obtained. The relationship between the stress threshold $\left(\sigma_{c c}, \sigma_{c i}, \sigma_{c s}\right.$, and $\left.\sigma_{c d}\right)$ of each stage and the uniaxial compressive strength $\sigma_{U C S}$ of rock samples in the whole process of fracture is analyzed, which shows that the deformation characteristics and crack evolution law of the rock are unified. The research results can provide some reference for further understanding of rock damage evolution mechanism in engineering field.
\end{abstract}

\section{Introduction}

The excavation of the tunnel under the deep high ground stress environment breaks the original stress balance state, resulting in local stress concentration, which is very easy to cause rock burst disaster [1]. The safety of human life and property is seriously threatened by rock burst, rock loose, and even roadway instability. Rock burst disaster has become a bottleneck that restricts human beings to seek for mineral resources in the deep. There have been a lot of research studies on the mechanism and prediction of rock burst, but most of them still have some shortcomings. To better understand the mechanism of rock burst, it is necessary to clearly understand the stages of rock fracture. There are a large number of scholars [2-8] at home and abroad, through a variety of means to study the process of rock fracture in detail. It is revealed that the brittle fracture of rock is accompanied by the closure, development, propagation, and interpenetration of internal microcracks. Therefore, the macromechanical properties of rock are closely related to the development of internal microcracks.
Brace et al. $[2,3,9,10]$ have defined five stages of rock failure, as follows: (1) crack closure (closing of cracks) deformation (0- $\left.\sigma_{c c}\right)$; (2) linear elastic deformation $\left(\sigma_{c c}-\sigma_{c i}\right)$; (3) crack (fracture) initiation and stable crack growth $\left(\sigma_{c i}{ }^{i} \sigma_{c d}\right)$; (4) critical energy release and unstable crack growth $\left(\sigma_{c d}-\sigma_{u c s}\right)$; and (5) failure and postpeak behavior (maximum deformation) ( $\sigma_{u c s}$-End) based on the stress-strain behavior under compression. Stage (1) is the initial loading stage, and the microcracks or micropores in the rock are closed under compressive stress. This stage depends on the distribution and morphology of microcracks in the rock at the initial state. Generally, the axial stress-strain curve in this stage shows strong nonlinear characteristics, and the volume deformation decreases correspondingly, indicating that the rock is in the compression state. Stage (2) shows approximate linear elastic characteristics, and axial strain and volume strain are linear. It shows that the microcracks in the rock are closed and still in the compression state. This stage can be used to determine Young's modulus and Poisson's ratio of rock. In stage (3), as the axial difference stress continues to 
increase, the volume strain curve begins to deviate from the straight line, the volume deformation of rock begins to increase, and the dilatancy phenomenon appears. In stage (4), the microcracks in the rock specimen developed and penetrated further, forming visible macrocracks gradually. The axial and lateral strain of the rock specimen continued to increase, and the volume expansion deformation began to accelerate. In the last stage, the accumulated elastic energy in the rock specimen is released, a large number of macrocracks are penetrated, and the rock specimen forms a fracture surface, causing damage. However, Eberhardt et al. [6] believes that the stable crack growth stage $\left(\sigma_{c i}-\sigma_{c d}\right)$ can be divided into two stages: the stage from the initial crack to crack interaction $\left(\sigma_{c i}-\sigma_{c s}\right)$ and the stage from the crack interaction to rock failure $\left(\sigma_{c s}-\sigma_{c d}\right)$. Therefore, according to this viewpoint, the process of rock fracture can be divided into six stages with five thresholds.

The detection of these thresholds, however, has proven difficult especially with respect to crack initiation. A large number of scientific methods have been tried to monitor the process of rock fracture. These techniques involve the use of stress-strain data and acoustic emission monitoring. The process of rock fracture contains abundant acoustic emission information, and the evolution of internal damage is closely related to acoustic emission. AE is directly related to the microfractures in rocks and can be expressed by the damage parameters of rocks. Because the AE signals contain abundant information about crack changes, a number of studies have used $\mathrm{AE}$ to investigate the evolution law of crack and rock fracture patterns in Brazilian splitting tests, three-point bending, and compression [11-19]. It is found that there are inevitably subjectivity and uncertainty in the process of determining rock deformation by using the crack volume strain method [20-25]. Thus, if we can identify the relationship between the stress levels and the AE signals in the laboratory or on-site, the damage degree, crack states, and stability of the rock specimen, rock mass, and pillars can be accurately assessed and evaluated. Yang et al. [26] carried out the triaxial compression acoustic emission experiment on limestone, analyzed the damage evolution characteristics of rock under triaxial compression by using the acoustic emission ring count, and established the damage evolution model of rock under triaxial compression based on the cumulative ring count of acoustic emission. Tan et al. [27] simulated the uniaxial compression test of heterogeneous coal-rock assemblage, which obeyed Weibull distribution by particle flow program. The change rule and duration of AE characteristics in different periods are affected by duration. The more inhomogeneous the coal-rock combination body is, the shorter the lasting time in booming period of AE characteristics will be. Zhang et al. [28] discussed the corresponding relationship between the fracture scale and the characteristics of acoustic emission signals and found that the large-scale fracture corresponds to the low frequency and high amplitude acoustic emission signals, while the small-scale fracture corresponds to the low frequency and low amplitude, medium frequency, high frequency, and low amplitude acoustic emission signals.
Based on the corresponding relationship between $\mathrm{AE}$ activity and rock damage evolution process, the rock damage state can be quickly understood by $\mathrm{AE}$ monitoring technology. In this paper, based on the previous studies, according to the Eberhardt et al. [6] stress threshold division criteria, the acoustic emission technology is applied to the uniaxial compression test of granite samples, to obtain the characteristic parameters of acoustic emission activity in the process of rock deformation and fracture and then to determine the threshold value of each stage of rock loading process before peak pressure. Additionally, the relationship between the thresholds and peaks was analyzed to establish a practical approach toward predicting the rock burst, large deformation of roadways, and rupture of pillars.

\section{Experimental Device and Rock Specimens}

2.1. Preparation of Specimen. Fifty cylindrical granite specimens were prepared for uniaxial compression testing. The granite specimens were cut and ground into rectangleshaped specimens with a size of $50 \times 50 \times 100 \mathrm{~mm}$ (length $\times$ width $\times$ height) and a height to width ratio of $2: 1$, according to the ISRM recommendations. The surface of both ends of the specimens shall be carefully polished to make the surface flatness within $0.01 \mathrm{~mm}$. The average size and the physical and mechanical parameters of the granite specimens are listed in Table 1.

2.2. Testing System and Apparatus. To test the rock group specimens, we utilized a testing system in the Rock Mechanics Laboratory of Northeastern University. This testing system includes the loading apparatus, recording system of stress-strain data, and a system for $\mathrm{AE}$ acquisition and analysis.

(1) Loading apparatus and conditions: the loading apparatus used in the experiment was a closed-loop electrohydraulic servo triaxial testing machine, as shown in Figure 1. The main parameters of this loading apparatus are as follows: (1) maximum axial force of $3000 \mathrm{kN}$ and the resolution of $20 \mathrm{~N}$; (2) the maximum axial deformation of the specimens is $8 \mathrm{~mm}$ and the resolution is $0.0005 \mathrm{~mm}$, while the maximum lateral deformation of the specimens is $8 \mathrm{~mm}$ and the resolution is $0.0005 \mathrm{~mm}$; (3) the stiffness of the frame was not less than $10 \mathrm{GN} / \mathrm{m}$; and (4) the loading process can be monitored by displacement or force, and the rock specimens used in this experiment were displaced at a speed of $0.06 \mathrm{~mm} / \mathrm{min}$.

(2) Collection system of data: during the experimental procedure, the force of the loading apparatus and the axial, lateral deformation were measured using the stress sensor and static strain gauges. The resolution of the external displacement sensor is $0.0001 \mathrm{~mm}$.

An AE transducer with an operating frequency range of $1 \mathrm{kHz}-1 \mathrm{MHz}$ and a nominal resonant frequency of $500 \mathrm{kHz}$ were used in the experiments. The AE system, which is 
TABle 1: Average size and parameters of physical and mechanical properties of granite samples.

\begin{tabular}{lccccc}
\hline Specimens & Height $(\mathrm{mm})$ & Width (length) $(\mathrm{mm})$ & Uniaxial compressive strength $(\mathrm{MPa})$ & Young's modulus $(\mathrm{GPa})$ & Poisson's ratio \\
\hline Granite rock & 100.33 & 50.63 & 113.5 & 72.16
\end{tabular}

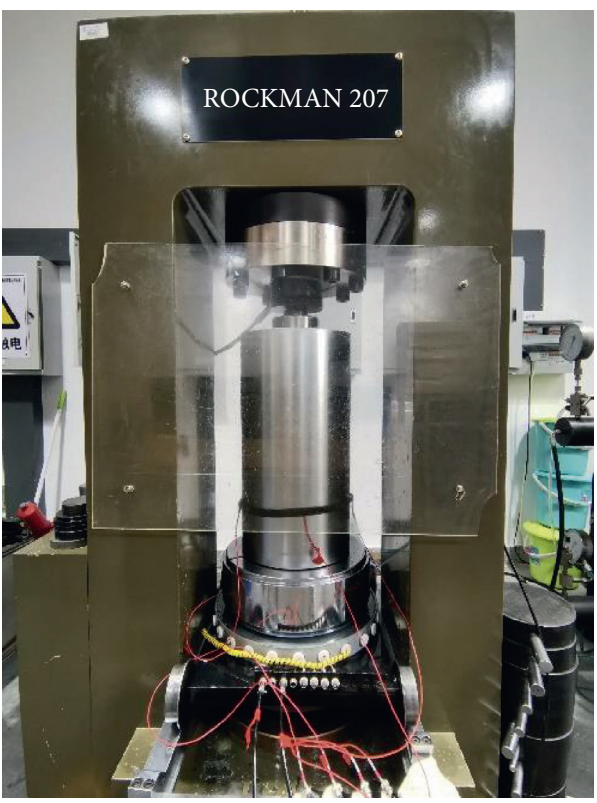

FIGURE 1: Loading system.

capable of the two-channel high-speed acquisition and analysis of $\mathrm{AE}$ signals, is called Pocket-AE (American Physical Acoustics Company). The AE system discussed below was used to acquire and analyze the signals. During the test, the acoustic emission sensor is closely attached to the specimens, and the contact part between the probe and the specimens is coated with a layer of Vaseline to ensure the coupling effect. To eliminate the end effects and reduce the noise from the pressing system of the loading apparatus, the contact interfaces between the indenter and the testing specimens were evenly coated with butter, and a $3-\mathrm{mm}$-thick filter plate was attached to both ends of the specimens. The AE monitoring system did not only digitize the signal waveform but also stored the features of each signal. Before testing, it was important to specify particular parameters to ensure the correct recording of the AE data. On the basis of the previous test, the reasonable AE parameters of uniaxial compression test are determined. The sampling frequency is $10 \mathrm{MHz}$, the gain is $30 \mathrm{~dB}$, the threshold value is $45 \mathrm{~dB}$, the impact definition time is $50 \mu \mathrm{s}$, the impact interval time is $300 \mu \mathrm{s}$, and the adjusted threshold voltage is $1.0 \mathrm{~V}$.

\section{Experimental Results and Discussion}

This study carried out analysis to classify the stages of rock deformation and failure defined by Brace et al. $[2,3,6]$, based on the characteristics of $\mathrm{AE}$ signals under uniaxial compression, such as the rate of AE events, energy, accumulation energy, and $\mathrm{AE}$ amplitude. As described previously, in the stable crack development stage, based on the axial and lateral changes of the rock specimens and the AE signal characteristics, we could further classify the stable development stage into two parts: the stage from the initial crack to crack interaction $\left(\sigma_{c i}-\sigma_{c s}\right)$ and the stage from the crack interaction to rock failure $\left(\sigma_{c s}-\sigma_{c d}\right)$.

3.1. Pre-Existing Crack Closure. Rock is not a homogeneous body, since it contains many gaps such as tiny cracks, lattice gaps, flaws, and other defects. The crack closure threshold $\left(\sigma_{c c}\right)$ is defined as the critical value of the rock from a preexisting crack stage to the linear elastic stage under uniaxial compression. In the stress-strain curve, the critical point prior to the linear elastic deformation is determined by the axial strain changes, from nonlinear to linear behavior. When the primary fracture in the rock sample is closed, the fracture contact surface will occlude, which will cause sporadic acoustic emission phenomenon. Compared with the acoustic emission information in the whole failure of the rock sample, its frequency and energy value are very small. In addition, the cumulative energy of $\mathrm{AE}$ is low, but the energy rate hardly fluctuates. These characteristics indicate that the strain energy stored in the rock specimens manifests as elastic waves of small energy during the crack closure process (Figure 2).

Characteristically, as the rate of $\mathrm{AE}$ events changes, the energy rate also changes, and the consistency of the $\mathrm{AE}$ events and energy release per unit of time become identical. In other words, a dislocation source (for example, crack closure or movement) can cause the displacement of lattices and also trigger an AE event. Additionally, the number of dislocation sources results in the same number of $\mathrm{AE}$ events, and the energy released by each $\mathrm{AE}$ event at this stage is approximately equal. The three abovementioned factors result in the AE event rate and energy rate being remarkably consistent. At this stage, the amplitude and duration of a single $\mathrm{AE}$ event are significantly correlated with the variation of AE event rate (Figures 3 and 4). The duration of AE events was longer at the beginning of loading and then decreased gradually. The amplitude and rate of single AE event decrease with the increase of loading pressure, and the released energy rate is very low in the whole process. Thus, the features with the longer duration and larger amplitude causing the higher rate of $\mathrm{AE}$ events in the crack closure stage are in agreement with the general characteristics of the rock specimens because many pre-existing cracks continued to close at lower stress. Because the original rock defects gradually closed with the increase of axial stress, the heterogeneity of the rock specimens eventually decreased to reach the linear elastic phase.

Naturally, the difficulty of using the stress-strain data to identify the crack closure threshold depends on the different rock types. For instance, some brittle rocks are not easy to condense, while, for other rocks, condensation is relatively easy. Therefore, we can use the changes in Young's modulus 


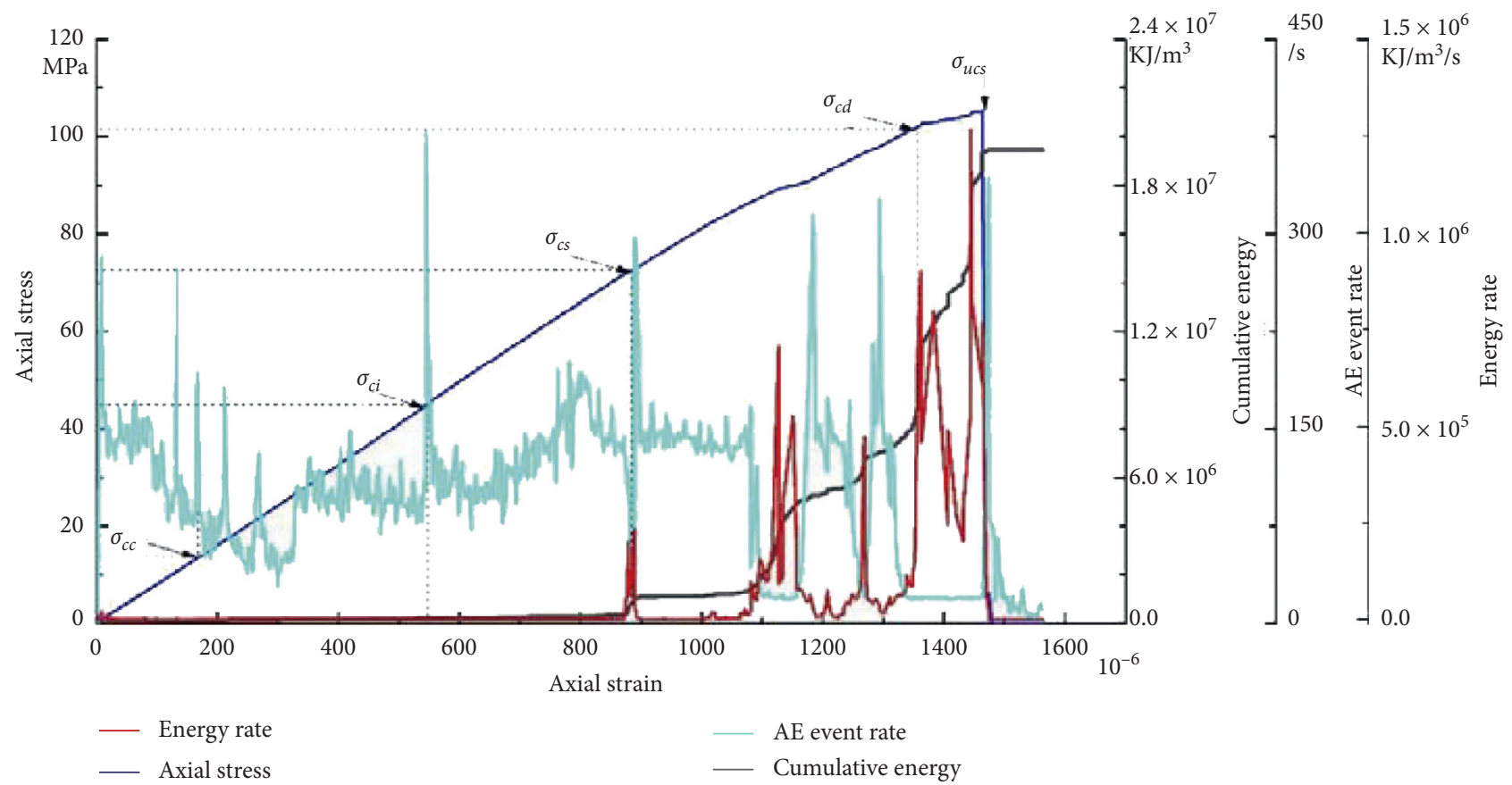

Figure 2: Stress, acoustic emission event rate, cumulative energy, and energy rate versus strain curves.

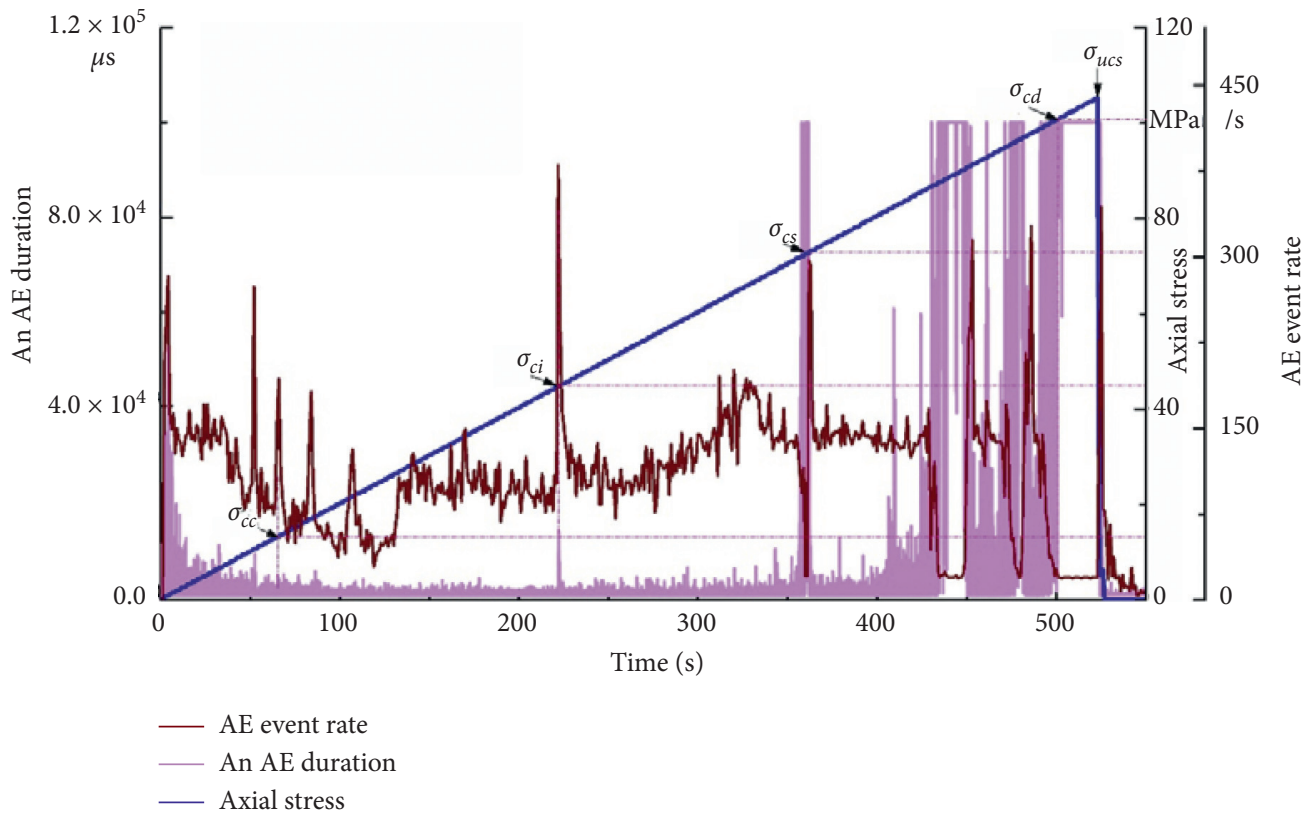

Figure 3: AE event rate, AE duration, and stress versus time curves.

of the rock during the rock deformation process to determine the crack closure stress threshold. To reduce the error caused by the mutations of the individual point and human subjectivity, we can define the average value of five points around a single point at the threshold of crack closure.

It can be seen from Figures 3-5 that the threshold values are 13.47 $\mathrm{MPa}$ and 15.23 $\mathrm{MPa}$, respectively, when using the $\mathrm{AE}$ characteristics method and the deformation characteristics approach. The results are slightly different; therefore, we can see that the two methods for determining the crack closure thresholds are similar, although they are based on different concepts. Additionally, crack closure threshold $\left(\sigma_{\mathrm{cc}}\right)$ of the specimen was $14.35 \mathrm{MPa}$.

3.2. Behavior of Linear Elastic Deformation. When the stress exceeded the crack closure threshold $\left(\sigma_{c i}\right)$, the rock specimens entered the elastic stage. At this stage, as the axial stress increases, the axial strain stiffness, that is, Young's modulus, tends to be constant (Figure 5). In Figure 2, we can observe 


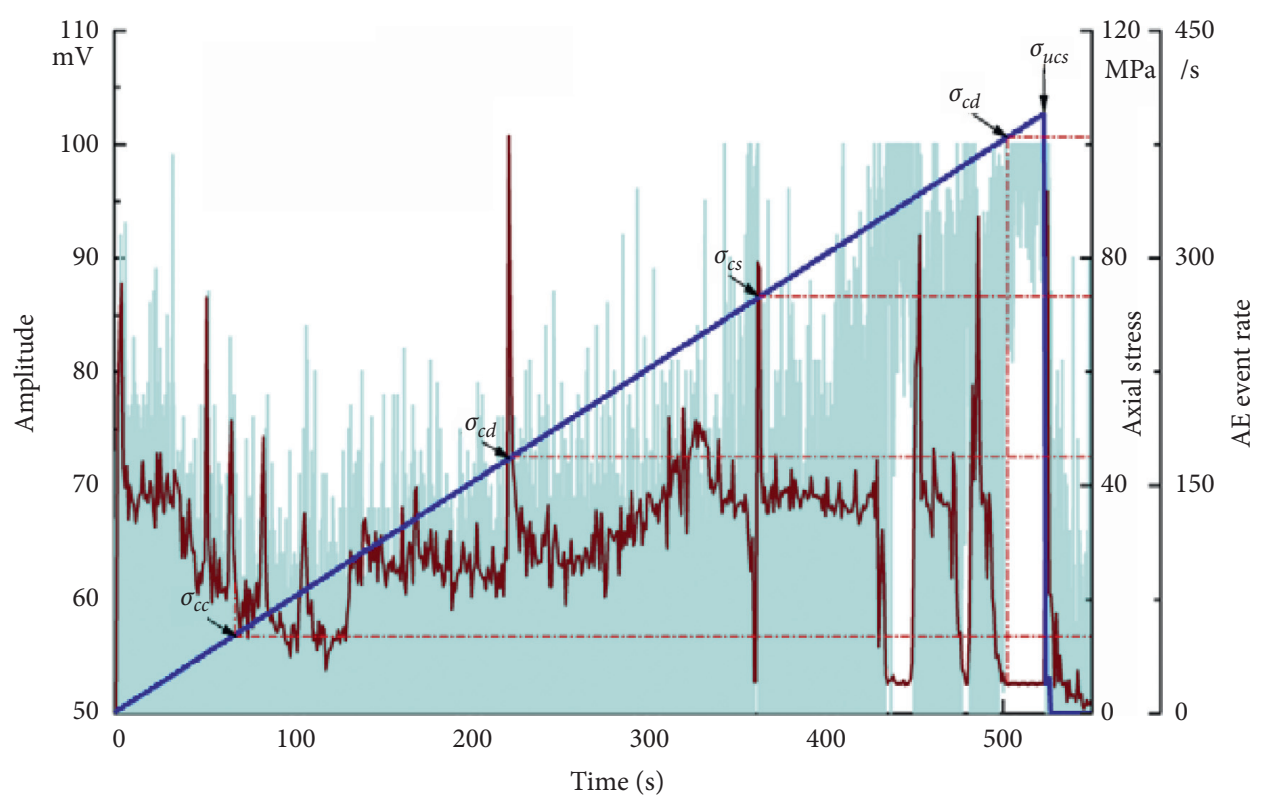

An event amplitude

- AE event rate

_ Axial stress

Figure 4: AE event rate, amplitude, and stress versus time curves.

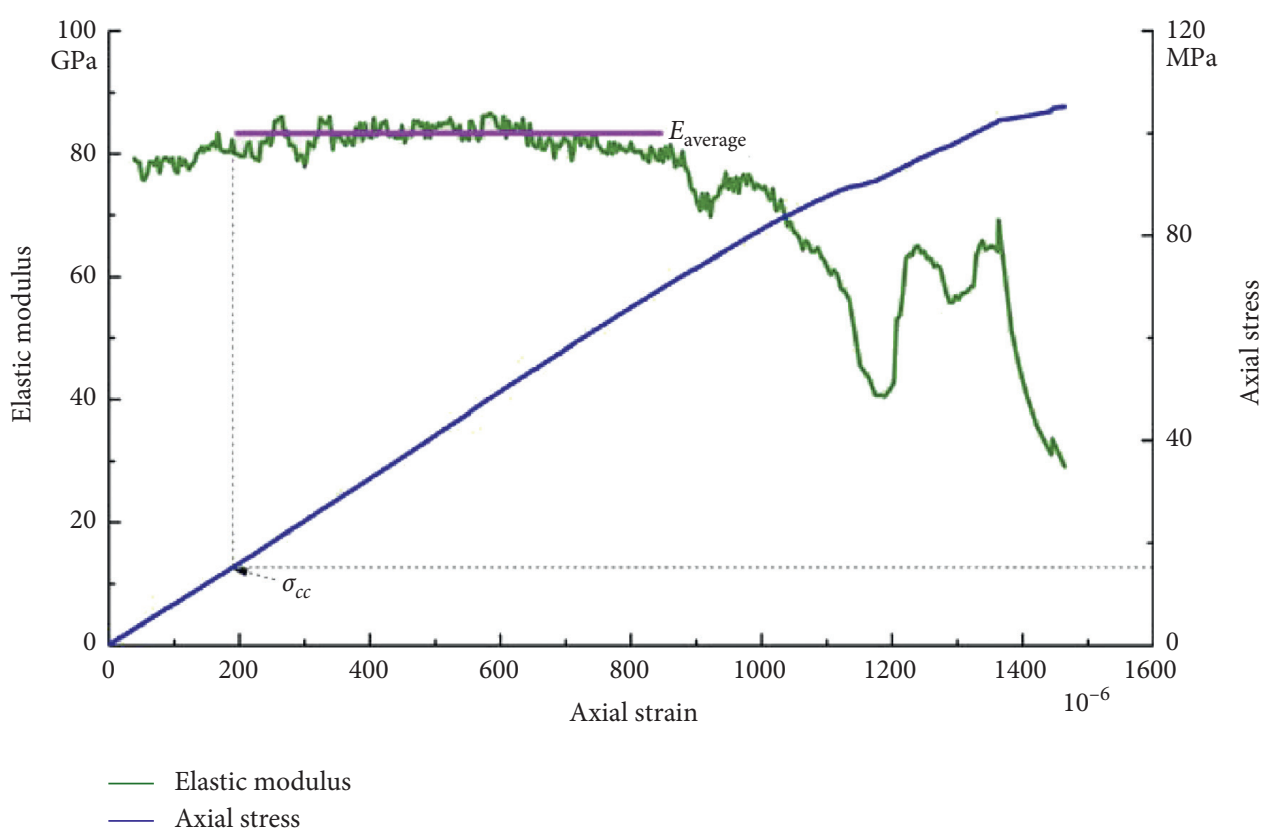

FIgURE 5: Young's modulus and stress versus strain curves.

various characteristics of the $\mathrm{AE}$ signals: lower and smaller $\mathrm{AE}$ events; nonincreasing cumulative $\mathrm{AE}$ energy; and smaller and more even $\mathrm{AE}$ event duration, and lower $\mathrm{AE}$ amplitude compared with the crack closure phase (Figures 3 and 4). The differences between the linear elastic deformation and crack closure stages indicate that the rock specimen resembles the linear behavior of elastomer-like springs. The microfractures of the specimens were observed and the number and frequency of the released elastic waves were found to be less and lower, respectively. Thus, the AE signal characteristics can indicate the linear elastic stage. The release of elastic waves during the loading process can be induced by the movement of the crystal lattice and the stress concentration at the crack tips. For the coupling between the event rate and the amplitude of $\mathrm{AE}$ signals, both variations with time were reasonably consistent (Figures 3 and 4).

At the late linear elastic stage, the AE event rates sharply increased and the amplitude and duration of the $\mathrm{AE}$ signals 
increased in a similar manner. These features suggest that the original defects had been closed in the rock specimens, but then recovered and entered the initiation stage. Thus, depending on the changes o AE signal characteristics, we can determine that the rock specimens reached the stress threshold of crack initiation. Additionally, the crack initiation stress threshold $\left(\sigma_{c i}\right)$ of the specimen was $45.01 \mathrm{MPa}$.

3.3. Crack Initiation and Development. As the axial load increased, the cracks constantly initiated, developed, and ruptured. The stage between the development of the original independent single crack and the mutual influence of the adjacent range cracks is called the microcrack stage.

In the initial stage of microcracks, while the values of the $\mathrm{AE}$ event rate and the variation margin were high and large, respectively, the cumulative energy and energy rate remained approximately unchanged (Figure 2). This suggests that the number of microcracks was high; however, the smaller crack volume and lower elastic wave energy stored in the crack tip means that the rock specimens remained in a stable phase. From another viewpoint, the AE signal characteristics, such as the short duration and high magnitude of events can also reflect the crack status and development. At the stress threshold of crack initiation, the stress-strain curve slightly deviated from an oblique straight line. However, the stress continued to increase and the rock specimen surfaces did not exhibit significant breakdown. These characteristics imply that the rock was also stable.

In the later stage of crack growth, there are abrupt changes in $\mathrm{AE}$ event rate, cumulative energy, energy rate, duration of single $\mathrm{AE}$ event, and $\mathrm{AE}$ event amplitude (Figures 2-4). This suggests that the microcracks expanded from independent development to the interaction of two or multiple adjacent cracks, and the rock specimens had large body defects in their interior, which affected their macroperformance. These weaknesses provided some space for the penetration of the rupture surface. From the AE characteristic, it can be determined that the stress threshold $\left(\sigma_{c s}\right)$ of the crack interaction for the specimen was $92.58 \mathrm{MPa}$.

3.4. Interaction of Cracks. The microcracks began to interact with other cracks, while the AE signals underwent substantial changes. At this stage, the event rates of the $\mathrm{AE}$ signals and change ranges were much larger compared with previous stages. Additionally, the accumulated energy rapidly increased, and the rate of energy also underwent several mutations. The subgradient increase of the accumulated energy indicates that, as brittle as granite is, the instability of rock rupture was not caused by mutation, but rather by gradual damage.

There existed an interesting phenomenon whereby the high rates and the large amplitude of the AE events were associated with long duration in a certain period. Particularly, the long duration and large amplitude of the AE event corresponded to low event rates during the occurrence of large cracks (Figures 3 and 4). The feature of the AE signals was considered as the basis for determining the occurrence of large cracks and was termed as the calm stage before rock fracturing.

3.5. Crack Damage and Critical Energy Release. The accumulated energy during the crack interaction stage underwent several mutations. Hence, we defined the corresponding stress value of the last mutation point as the cracking fracture damage threshold (Figures 3 and 4). According to the characteristics of the AE event, the damage stress threshold $\left(\sigma_{c s}\right)$ for specimen was $101.70 \mathrm{MPa}$. In the stage of crack aggregation before this mutation point, the energy of the specimen is released and no large-scale fracture occurs, which indicates that the rock specimen does not really penetrate into the fracture surface. From Figures 2 and 3 , it can be seen that the single $\mathrm{AE}$ event at the mutation point has a long duration and a very high amplitude, indicating that there is a large crack formation and the fracture surface is through at this point.

3.6. Unstable Development of Cracks and Peak Failure. The unstable development of rock fracture resulted from the appearance of large cracks in the formation of the final through-plane. At this stage, the AE characteristics had unique features: small event rates, high accumulated energy, big amplitude, and long event duration (Figures 2-4). This occurred because, when a sizable crack appeared and the number of large cracks was small, the released energy of every crack rupture was relatively high. The inflection points of the stress-strain curve from the point of increase to the point of decrease is the peak strength. Thus, the peak strength of the specimen was $105.30 \mathrm{MPa}$.

\subsection{Relationship between Each Threshold and Peak Strength.} According to the abovementioned method, we can use the characteristics of the AE signals during the axial loading to determine each stress threshold and calculate the ratio of each threshold versus the peak strength. Naturally, the stress threshold can be determined by the observed deformation of the rock specimens or by carrying out energy calculations. The results obtained by each of these methods are presented in Table 2.

For the rock in this experiment, when the load reaches $13 \%$ of the peak strength, the rock enters the stage of linear elasticity, and when the load reaches $55 \%$, the crack begins to sprout and expand. It should be noted that when the stress is loaded to $90 \%$ of the peak strength, the grains of the rock specimen will be crushed, the macrocracks will be produced, and the specimen will move along the fracture surface. This result proves that the method of acoustic emission is correct to determine the rock fracture threshold. By comparing the ratio of stress threshold to peak intensity calculated by Bieniawski [3] based on the energy accumulation during uniaxial compression with the ratio of stress threshold to peak intensity calculated by the acoustic emission characteristic parameters during uniaxial compression, we determined that the former was smaller by $10 \%$ compared with the latter. It is believed that this is because granite is a typical 
TABLE 2: Average values of percentages of various stress thresholds versus peak strength for rock samples.

\begin{tabular}{|c|c|c|c|c|}
\hline Specimens & $\begin{array}{c}\text { Percentage of crack } \\
\text { closure versus peak } \\
\text { strength (\%) }\end{array}$ & $\begin{array}{c}\text { Percentages of crack } \\
\text { initiation versus peak } \\
\text { strength }(\%)\end{array}$ & $\begin{array}{c}\text { Percentages of crack } \\
\text { interaction versus peak } \\
\text { strength }(\%)\end{array}$ & $\begin{array}{l}\text { Percentages of crack damage } \\
\text { versus peak strength }(\%)\end{array}$ \\
\hline This study & 12.82 & 54.41 & 74.50 & 90.76 \\
\hline Tradition [3] & - & $\approx 35$ & ----- & $\approx 80$ \\
\hline $\begin{array}{l}130 \mathrm{~m} \text { level Pink } \\
\text { Granite [6] }\end{array}$ & 16.88 & 46.22 & & 75.23 \\
\hline $\begin{array}{l}240 \mathrm{~m} \text { level Pink } \\
\text { Granite [29] }\end{array}$ & 18.91 & 40.63 & & 76.37 \\
\hline Gabbro [30] & 15.39 & 31.85 & & 73.87 \\
\hline $\begin{array}{l}\text { Yeosan Marble } \\
{[31]}\end{array}$ & 19.66 & 34.45 & & 92.32 \\
\hline
\end{tabular}

brittle rock and its deformation characteristics are not obvious. Thus, every stress threshold is allowed to be high.

\section{Conclusion}

This study carried out AE testing by uniaxial compression experiments for a granite group of samples and combined the stress-strain curves and parameters of AE signals in the time dimension. Thus, the stress threshold was determined for each sample throughout the rupture process, and the following conclusions were drawn:

(1) In the process of specimen loading, the rate of $\mathrm{AE}$ events in the crack growth stage is low, the duration of single AE event is long and the amplitude is large, and the mutation of energy rate occurs. These phenomena can be used as the basis for judging the formation of macrocracks.

(2) The crack closure, initiation, development, aggregation, and temporal evolution of rupture under compression are reflected on the information stored in the AE event signals. Therefore, the method based on the AE characteristics is reliable and accurate.

(3) Under the action of low stress level, although there are microcracks in the rock, the acoustic emission ring count and energy are relatively small, indicating that the low stress level has little influence on the stability of the rock structure.

(4) The stress threshold of each stage of rock fracture can be combined with the acoustic emission monitoring of the engineering site, which provides a reliable basis for the monitoring and prediction of rock burst in the next step.

\section{Data Availability}

The data used to support the findings of this study are included within the article.

\section{Conflicts of Interest}

The authors declare no conflicts of interest.

\section{Acknowledgments}

This work was supported by the project of NSFC Shandong United Fund (U1806208) and National Key Research and Development Program (2016YFC0600803, 2018YFC0604401, and 2018YFC0604604) and the Fundamental Research Funds for the Central Universities (N2001033).

\section{References}

[1] Y. B. Zhang, J. Li, X. X. Liu, and B. Z. Tian, "Infrared radiation portentous characteristics of rock burst in roadway," Journal of Mining \& Safety Engineering, vol. 32, no. 5, pp. 786-792, 2015.

[2] W. F. Brace, B. W. Paulding, and C. Scholz, "Dilatancy in the fracture of crystalline rocks," Journal of Geophysical Research, vol. 71, no. 16, pp. 3939-3953, 1966.

[3] Z. T. Bieniawski, "Mechanism of brittle fracture of rock," International Journal of Rock Mechanics and Mining Sciences \& Geomechanics Abstracts, vol. 4, no. 4, pp. 395-406, 1967.

[4] E. Z. Lajtai and V. N. Lajtai, "The evolution of brittle fracture in rocks," Journal of the Geological Society, vol. 130, no. 1, pp. 1-16, 1974.

[5] C. D. Martin and N. A. Chandler, "The progressive fracture of Lac du Bonnet granite," International Journal of Rock Mechanics and Mining Sciences \& Geomechanics Abstracts, vol. 31, no. 6, pp. 643-659, 1994.

[6] E. Eberhardt, D. Stead, B. Stimpson, and R. S. Read, "Identifying crack initiation and propagation thresholds in brittle rock," Canadian Geotechnical Journal, vol. 35, no. 2, pp. 222-233, 1998.

[7] M. Cai, P. K. Kaiser, Y. Tasaka, T. Maejima, H. Morioka, and M. Minami, "Generalized crack initiation and crack damage stress thresholds of brittle rock masses near underground excavations," International Journal of Rock Mechanics and Mining Sciences, vol. 41, no. 5, pp. 833-847, 2004.

[8] M. S. Diederichs, P. K. Kaiser, and E. Eberhardt, "Damage initiation and propagation in hard rock during tunnelling and the influence of near-face stress rotation," International Journal of Rock Mechanics and Mining Sciences, vol. 41, no. 5, pp. 785-812, 2004.

[9] Z. T. Bieniawski, "Propagation of brittle fracture in rock," in Proceedings of the 10th U.S. Symposium on Rock Mechanics (USRMS), pp. 409-427, Austin, TX, USA, May 1972.

[10] Z. T. Bieniawski and W. L. Van Heerden, "The significance of in situ tests on large rock specimens," International Journal of Rock Mechanics and Mining Sciences \& Geomechanics Abstracts, vol. 12, no. 4, pp. 101-113, 1975. 
[11] Z. Z. Liang, C. A. Tang, and M. L. Huang, "Numerical simulation of acoustic emission patterns in rock fracture," Northeastern University (Natural Science), vol. 23, no. 10, pp. 1008-1011, 2002.

[12] D. Lock, "The role of acoustic emission in the Study of rock fracture," International Journal of Rock Mechanics and Mining Sciences \& Geomechanical Abstracts, vol. 30, no. 7, pp. 880899, 1993.

[13] X. D. Zhao, Y. H. Li, and R. F. Yuan, "Study on dynamic evolution process of rock based on AE location," Chinese Journal of Rock Mechanics and Engineering, vol. 26, no. 5, pp. 944-950, 2007.

[14] D. Ma, Y. Zhou, and C. X. Liu, "Creep behavior and acoustic emission characteristics of coal samples with different moisture content," Acta Geodynamica et Geomaterialia, vol. 15, no. 4, pp. 405-412, 2018.

[15] Y. Yang, Y. Zhou, D. P. Ma, H. Y. Ji, and Y. D. Zhang, "Acoustic emission characteristics of coal under different triaxial unloading conditions," Acta Geodynamica et Geomaterialia, vol. 17, no. 1, pp. 51-60, 2020.

[16] E. Aker, D. Kühn, V. Vavryčuk, M. Soldal, and V. Oye, "Experimental investigation of acoustic emissions and their moment tensors in rock during failure," International Journal of Rock Mechanics and Mining Sciences, vol. 70, no. 9, pp. 286-295, 2014.

[17] S. G. Cao, Y. B. Liu, and L. Q. Zhang, "Study on characteristics of acoustic emission in outburst coal," Chinese Journal of Rock Mechanics and Engineering, vol. 26, no. 1, pp. 2794-2799, 2007.

[18] H. Sun, X. L. Liu, and J. B. Zhu, "Correlational fractal characterisation of stress and acoustic emission during coal and rock failure under multilevel dynamic loading," International Journal of Rock Mechanics \& Mining Sciences, vol. 117, no. 5, pp. 1-10, 2017.

[19] W. Wang, H. Wang, D. Y. Li, H. M. Li, and Z. M. Liu, "Strength and failure characteristics of natural and watersaturated coal specimens under static and dynamic loads," Shock and Vibration, vol. 2018, Article ID 3526121, 15 pages, 2018.

[20] Y. Gong, Z. Song, M. He, W. Gong, and F. Ren, "Precursory waves and eigenfrequencies identified from acoustic emission data based on Singular Spectrum Analysis and laboratory rock-burst experiments," International Journal of Rock Mechanics and Mining Sciences, vol. 91, no. 1, pp. 155-169, 2017.

[21] W. Mu, L. Li, T. Yang, G. Yu, and Y. Han, "Numerical investigation on a grouting mechanism with slurry-rock coupling and shear displacement in a single rough fracture," Bulletin of Engineering Geology and the Environment, vol. 78, no. 8, pp. 6159-6177, 2019.

[22] Z. H. Chen, L. H. Tham, and H. Xie, "Experimental and numerical study of the directional dependency of the Kaiser effect in granite," International Journal of Rock Mechanics and Mining Sciences, vol. 44, no. 77, pp. 1053-1061, 2007.

[23] Q. Ma, Y. L. Tan, X. S. Liu, Q. H. Gu, and X. B. Li, "Effect of coal thicknesses on energy evolution characteristics of roof rock-coal-floor rock sandwich composite structure and its damage constitutive model," Composites Part B: Engineering, Article ID 108086.

[24] M. Seto, M. Utagawa, and K. Katsuyama, "Application of acoustic emission technique to determination of in-situ stresses in mines," in Proceedings of the Safety in Mines Research Institute, Central Mining Institute, Katowice, Poland, pp. 691-696, 1997.
[25] X. Kong, E. Wang, S. Hu, R. Shen, X. Li, and T. Zhan, "Fractal characteristics and acoustic emission of coal containing methane in triaxial compression failure," Journal of Applied Geophysics, vol. 124, no. 1, pp. 139-147, 2016.

[26] Y. J. Yang, D. C. Wang, M. F. Guo, and B. Li, "Study of rock damage characteristics based on acoustic emission tests under triaxial compression," Chinese Journal of Rock Mechanics and Engineering, vol. 33, no. 1, pp. 98-104, 2014.

[27] Y. L. Tan, W. Y. Guo, Q. H. Gu et al., "Research on the rockburst tendency and $\mathrm{AE}$ characteristics of inhomogeneous coal-rock combination bodies," Shock and Vibration, vol. 2016, Article ID 9271434, 11 pages, 2016.

[28] Y. B. Zhang, P. Liang, B. Z. Tian, X. L. Yao, and L. Sun, "Multi parameter coupling analysis of acoustic emission signals of granite disaster and the precursor characteristics of the main rupture," Chinese Journal of Rock Mechanics and Engineering, vol. 35, no. 11, pp. 2248-2258, 2016.

[29] C. D. Martin, Strength of Massive Lac du Bonnet Granite Around Underground Openings, University of Manitoba, Manitoba, Canada, 1993.

[30] K. A. Barry and D. R. Rees, "Acoustic emission during stress corrosion cracking in rocks," in Maurice Ewing Series, D. W. Simpson and P. G. Richards, Eds., American Geophysical Union, Washington, DC, USA, pp. 605-616, 1981.

[31] S.-H. Chang and C.-I. Lee, "Estimation of cracking and damage mechanisms in rock under triaxial compression by moment tensor analysis of acoustic emission," International Journal of Rock Mechanics and Mining Sciences, vol. 41, no. 7, pp. 1069-1086, 2004. 